\title{
An assessment of pancreatic endocrine function and insulin sensitivity in patients with transient neonatal diabetes in remission
}

\author{
J P H Shield, I K Temple, M Sabin, D Mackay, D O Robinson, P R Betts, D J Carson, H Cavé, \\ D Chevenne, M Polak
}

Arch Dis Child Fetal Neonatal Ed 2004;89:F341-F343. doi: 10.1136/adc.2003.030502

\begin{abstract}
See end of article for authors' affiliations Correspondence to:
Dr Shield, The Royal Hospital for Sick Children, St Michael's Hill, Bristol BS2 8BJ, UK; i.p.h.shield@ bristol.ac.uk
\end{abstract}

Accepted 9 July 2003

\begin{abstract}
Aims: To examine derived indices of $\beta$ cell function, peripheral insulin sensitivity, and the pancreatic response to intravenous glucose loading in children with a previous history of transient neonatal diabetes currently in remission, repeated after a period of two or more years.

Methods: The standard intravenous glucose tolerance test (IVGTT) was used to measure the first phase insulin response (FPIR) cumulatively at one and three minutes. In addition, fasting insulin and glucose values were used to estimate insulinogenic indices ( $\beta$ cell function) and QUICKI (insulin sensitivity).

Patients: Six patients with known previous transient neonatal diabetes currently in remission with no exogenous insulin requirement were tested. Control data from 15 children of a similar age were available for derived fasting indices of $\beta$ cell functional capacity and insulin sensitivity.

Results: One child had a subnormal insulin secretory response to intravenous glucose that remained abnormal two and four years later. The other children had relatively normal or entirely normal responses over two years. Measures of $\beta$ cell function and insulin sensitivity in the fasting state showed comparable results to those obtained from normal controls.

Conclusions: Most children with transient neonatal diabetes in remission have no evidence of $\beta$ cell dysfunction or insulin resistance in the fasting state, although they might have been expected to show subtle defects given the tendency to relapse in adolescence. Measures of insulin response to intravenous glucose loading are often normal but suggest future recurrence if profoundly abnormal.
\end{abstract}

$\mathrm{T}$ ansient neonatal diabetes mellitus (TNDM) is a rare condition occurring in about 1:400 000 live births. It is usually characterised by intrauterine growth retardation and the development of insulin dependent diabetes in the first week of life, which resolves within three months. ${ }^{12}$ We have shown that diabetes remission is only a temporary phenomenon in most patients, with more than $60 \%$ relapsing at a median age of 14 years. ${ }^{3}$ The relapse is characterised by a variable requirement for exogenous insulin and negative autoimmune screening, suggesting a condition unlike classical type I diabetes. ${ }^{3}$

Studying two groups of patients from the United Kingdom and France, we have identified three distinct genetic rearrangements that cause TNDM. The first described was paternal uniparental isodisomy (UPD) of chromosome 6 in which two haploidentical copies of chromosome 6 are inherited from the father with no contribution from the mother. ${ }^{5}$ In the UK cohort, UPD6 is found in about a third of cases. The second cause of TNDM is an unbalanced duplication of part of paternal chromosome 6 in the region $6 \mathrm{q} 24$, constituting a further third of UK cases. ${ }^{67}$ With this rearrangement, children inherit a small extra segment of paternal chromosome 6 , which makes them liable to neonatal diabetes. Only if this duplication comes from the father does inheritance result in diabetes, suggesting that the gene(s) is imprinted. Most recently we have shown differential methylation at a CpG site (the biological site where methylation occurs) within the critical region and adjacent to a gene, ZAC, a candidate gene for TNDM. Controls have a methylated maternal and unmethylated paternal allele, and in cases of paternal UPD6 cases there are two paternal unmethylated alleles. We have subsequently shown that about $10 \%$ of cases have a methylation pattern identical with paternal UPD6 cases in the absence of UPD. ${ }^{8}$

The physiological basis of the remission and later relapse is largely unknown. However, the candidate overexpressed gene in TNDM-ZAC appears to regulate both cell cycle arrest and apoptosis, ${ }^{9}$ as well as the pituitary adenylate cyclase activating polypeptide receptor type I, this polypeptide being a potent insulin secretagogue. ${ }^{10}{ }^{11}$ Consequently, a reduction in absolute $\beta$ cell numbers or defect in insulin secretory capacity may underlie the clinical course. The aim of this study was to examine if subtle defects in pancreatic insulin secretion, using fasting insulin and glucose modelling and the first phase insulin response to intravenous glucose, could be identified in patients with a history of TNDM when they were in remission and whether these findings could be used to predict long term outcome and likelihood of relapse. These studies were conducted as part of the continuing clinical evaluation of the children, given the likelihood of later relapse, after informed consent was received from the parents. Our hypothesis was that, because most patients with TNDM in remission relapse in later life, we might expect to find subtle defects in pancreatic function during this period of clinical remission.

\section{PATIENTS AND METHODS}

Six patients were identified from the United Kingdom and France who had TNDM as neonates that had resolved within seven months of birth leaving the patients currently well,

Abbreviations: IVGT, intravenous glucose tolerance test; QUICKI, quantitative insulin sensitivity check index; TNDM, transient neonatal diabetes mellitus; UPD, uniparental isodisomy 
receiving no treatment, and defined by us as "in remission". None had pancreatic exocrine deficiency. There were four boys, and the median age was 7.5 years (range 3-11). Four were white, one had parents who originated from North Africa, and one had parents from Asia. Genetic anomalies were searched for as already described using genomic DNA of the subject and parents. ${ }^{67}$ Two of the patients had UPD6, and another had a methylation imprint defect. The remaining three patients had no identifiable genetic abnormality of chromosome 6. All had normal fasting plasma glucose concentrations and age related body mass indices. The patients all had an intravenous glucose tolerance test (IVGTT) in their local hospital according to a standardised protocol. ${ }^{12}$ They fasted from midnight on the day before and were tested at 9am in the morning. Two cannulae were positioned, one for $25 \%$ glucose administration at a dose of $0.5 \mathrm{~g} / \mathrm{kg}$ (to maximum of $35 \mathrm{~g}$ ), and the second for venous sampling. The glucose infusion was given over three minutes \pm 15 seconds. Samples for measuring serum glucose and insulin concentrations were taken at times $\mathrm{T}-5$, T0, and $\mathrm{T}+1,3,5,10$ minutes. First phase insulin response was calculated as the sum of $\mathrm{T}+1$ and +3 minute insulin concentrations. ${ }^{12}$ Insulin measurements were performed in a central laboratory (Paris) using a specific immunoradiometric assay with a detection limit of about $0.5 \mathrm{mIU} / \mathrm{l}$ (Bi-Insulin IRMA; Biorad-Pasteur (formerly Sanofi-Pasteur) Diagnostics). The intra-assay coefficient of variation is $<4 \%$, and the interassay coefficient of variation is $<6.5 \%$. The normal range for insulin response, according to age, was derived from Robert et al. ${ }^{13}$ Fasting proinsulin was measured at $\mathrm{T}-5$ minutes using a previously described inhouse immunoradiometric assay. ${ }^{14} 15$

The fasting glucose and insulin concentrations were also used to assess $\beta$ cell function and insulin sensitivity to derive an insulinogenic index (for $\beta$ cell function) and quantitative insulin sensitivity check index (QUICKI), which have recently been validated against hyperglycaemic and euglycaemic clamp studies in children. ${ }^{16}$ Fifteen lean, non-diabetic children (ages 4-10) were used as controls for this analysis. They had been recruited for a study of childhood adipocyte function with approval of the local ethics committee after parental consent was obtained. Insulin sensitivity and $\beta$ cell function tests were analysed between cases and controls using an unpaired $t$ test and in cases over time using a paired $t$ test (SPSS for windows).

\section{RESULTS}

In all cases, fasting glucose concentration was within the normal range. Compared to the controls of a similar age, children with TNDM in remission had normal $\beta$ cell function with normal insulin sensitivity using the insulinogenic index and QUICKI (table 1). In addition, in only one case was the first phase insulin response below the 5th centile for age matched historical controls (fig 1 ). ${ }^{13}$ Furthermore, repeated testing with a two year interval did not show any significant changes in terms of $\beta$ cell function, insulin sensitivity, or first

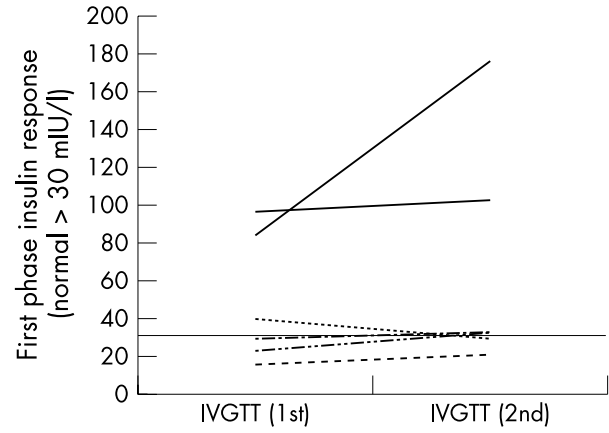

Figure 1 First phase insulin response (normal $>30 \mathrm{mlU} / \mathrm{l}$ ) to intravenous glucose in the six cases of transient diabetes mellitus in remission over an interval of two years. The horizontal line represents the 5th centile from historical controls without diabetes. ${ }^{13}$ The dashed line shows the response of the child who developed impaired glucose tolerance on the oral glucose tolerance test. IGTT, Intravenous glucose tolerance test.

phase insulin responses on IVGTT. The ratios of proinsulin to insulin were normal in all the children (not shown).

\section{DISCUSSION}

In 1972, Schiff $e t$ al ${ }^{17}$ reported the results of serial IVGTTs on a child in remission from TNDM and found entirely normal responses over a two year period. However, at least 60\% (11/ 18 cases) of children in the UK TNDM cohort have relapsed at a median age of 14 years (range 4-25) as well as five of seven children over the age of 8 in the French TNDM cohort, so we expected to be able to identify subtle defects in IVGTT responses or pancreatic $\beta$ cell function from within our remission group. ${ }^{23}$ In one case (fig 1, dashed line), there was evidence of a significantly reduced insulin response to intravenous glucose with a normal insulinogenic index comparative to controls, which may or may not indicate defective pancreatic function. The patient's first IVGTT at the age of 6 was abnormal with a normal oral glucose tolerance test. Contemporaneous with his second abnormal IVGTT two years later, he had developed impaired glucose tolerance on oral glucose challenge (two hour blood glucose $8 \mathrm{mmol} / \mathrm{l}$ ) which worsened over a further two years (oral glucose tolerance test: two hour glucose $10.2 \mathrm{mmol} / \mathrm{l}$ ) with no apparent worsening of his IVGTT.

Our results confirm the original findings of Schiff et al in identifying essentially normal endocrine pancreatic function in the remission phase. We know that the neonatal period of diabetes is notable for a lack of insulin secretion in the face of pronounced hyperglycaemia. ${ }^{1}$ After this period, our cases seem to display normal $\beta$ cell function with no evidence of insulin resistance. The question remains why do many go on to develop later diabetes. The pancreas is not a physiologically static organ, with $\beta$ cells constantly undergoing degeneration and regeneration throughout life. ${ }^{18}$ Some preliminary studies

Table 1 Indices of pancreatic function and insulin sensitivity in cases of transient diabetes mellitus (TNDM) in remission over time and compared with non-diabetic controls

\begin{tabular}{|c|c|c|c|}
\hline \multirow{2}{*}{$\begin{array}{l}\text { Indices of pancreatic function/insulin } \\
\text { sensitivity }\end{array}$} & \multicolumn{2}{|l|}{ TNDM cases } & \multirow[b]{2}{*}{ Controls } \\
\hline & 1st assessment & 2nd assessment & \\
\hline $\begin{array}{l}\text { Median age (years) } \\
\text { Insulinogenic index } \\
\text { QUICKI }\end{array}$ & $\begin{array}{l}7.5(3-11) \\
0.038(0.015) \\
0.427(0.056)\end{array}$ & $\begin{array}{l}9(5-13) \\
0.057(0.038) \\
0.349(0.05)\end{array}$ & $\begin{array}{l}7.5(4-10) \\
0.045(0.02) \\
0.404(0.04)\end{array}$ \\
\hline
\end{tabular}

Values are median (range) or mean (SD). There was no significant difference between the 1st assessment and controls or between the 1st and 2nd assessments. QUICKI, Quantitative insulin sensitivity check index. 
in rats suggest that many new islets are formed early after birth and a second wave of neogenesis occurs around the time of weaning. ${ }^{19}$ If a similar process takes place in humans, it may explain the resolution of diabetes at about 3-4 months in infants with TNDM. Subsequently the normal interrelationship between replication, neogenesis, and apoptosis may become inefficient, possibly because of the long term overexpression of the ZAC gene in its role as a regulator of cell cycle arrest and apoptosis. This may then lead to the relapse of the diabetes even though $\beta$ cell function had remained apparently normal during the time of remission.

We conclude that many children with TNDM in remission have seemingly normal pancreatic function and peripheral insulin sensitivity. However, altered response to intravenous glucose would appear to predict recurrence of glucose intolerance. Given that most of our cases with TNDM will probably relapse, the IVGTT and derived fasting indices as described may not be sufficiently robust and sensitive tools to evaluate the risk of later diabetes recurrence. However, we would strongly recommend long term clinical follow up of these children, with particular attention being paid to glucose homoeostasis around the time of adolescence.

\section{Authors' affiliations}

J P H Shield, M Sabin, Institute of Child Health, University of Bristol, Upper Maudlin St, Bristol, UK

I K Temple, Wessex Regional Genetics Service, University of

Southampton, UK

D Mackay, D O Robinson, Wessex Regional Genetics Laboratory, Salisbury, UK

P R Betts, Department of Paediatrics, Southampton General Hospital, UK D J Carson, Department of Child Health, Queen's University of Belfast, Northern Ireland

H Cavé, Genetic Biochemistry, Robert Debré Hospital, Paris, France D Chevenne, Hormonal Biochemistry, Robert Debré Hospital, Paris, France

M Polak, Pediatric Endocrine Unit, Necker Enfants Malades Hospital, Paris, France

\section{REFERENCES}

1 Shield JPH, Gardner RJ, Wadsworth EJK, et al. Neonatal diabetes: a study of its aetiopathology and genetic basis. Arch Dis Child Fetal Neonatal Ed 1997;76:F39-42.

2 Metz C, Cave H, Bertrand AM, et al. Neonatal diabetes mellitus: chromosomal analysis in transient and permanent cases. J Pediatr 2002;141:483-9.

3 Shield JPH. Neonatal diabetes: new insights into aetiology and implications. Horm Res 2000;53(suppl 1):7-11.

4 Shield JPH, Howell WM, Temple IK. Neonatal diabetes. Diabetes Care 1997;20:1045-6.

5 Temple IK, James RS, Crolla JA, et al. An imprinted gene(s) for diabetes? Nat Genet 1995;9:110-12.

6 Temple IK, Gardner RJ, Robinson DO, et al. Further evidence for an imprinted gene for neonatal diabetes localised to chromosome 6q22-23. Hum Mol Genet 1996:5:1117-21.

7 Cave H, Polak M, Drunat S, et al. Refinement of the 6q chromosomal region implicated in transient neonatal diabetes. Diabetes 2000;49:108-13.

8 Gardner RJ, Mackay DJG, Mungall AJ, et al. An imprinted locus associated with transient neonatal diabetes mellitus. Hum Mol Genet 2000;9:589-96.

9 Spengler D, Villalba M, Hoffmann A, et al. Regulation of apoptosis and cell cycle arrest by Zacl, a novel zinc finger protein expressed in the pituitary gland and the brain. EMBO J 1997;16:2814-25.

10 Ciani E, Hoffmann A, Schmidt P, et al. Induction of the PAC1-R (PACAP-type I receptor) gene by p53 and Zac. Mol Brain Res 1999;69:290-4.

11 Yamaguchi N. Pituitary Adenylate Cyclase Activating polypeptide enhances glucose-evoked insulin secretion in canine pancreas in vivo. JOP $2001 ; 2: 306-16$.

12 Bingley PJ, Colman P, Eisenbarth GS, et al. Standardization of IVGTT to predict IDDM. Diabetes Care 1992;15:1313-16.

13 Robert JJ, Deschamps I, Chevenne D, et al. Relationship between first-phase insulin secretion and age, HLA, islet cell antibody status, and development of type I diabetes in 220 juvenile first-degree relatives of diabetic patients. Diabetes Care 1991;14:718-23.

14 Sobey WJ, Beer SF, Carrington CA, et al. Sensitive and specific two-site immunoradiometric assays for human insulin, proinsulin, 66-66 split and 3233 split proinsulins. Biochem J 1989;260:535-41.

15 Chevenne D, Leger J, Levy-Marchal C, et al. Proinsulin and specific insulin responses to an oral glucose tolerance test in a healthy population. Diabetes Metab 1998:24:260-1.

16 Uwaifo GI, Fallon EM, Chin J, et al. Indices of insulin action, disposal, and secretion derived from fasting samples and clamps in normal glucose-tolerant Black and White children. Diabetes Care 2002;25:2081-7.

17 Schiff D, Colle E, Stern L. Metabolic and growth patterns in transient neonatal diabetes. New Engl J Med 1972;287:119-22.

18 Bonner-Weir S. Life and death of the pancreatic $\beta$-cells. Trends Endocrinol Metab 2000;11:375-8.

19 Scalgia L, Smith FE, Bonner-Weir S. Apoptosis contributes to the involution of $\beta$-cell mass in the post-partum rat pancreas. Endocrinology 1995; 136:5461-8. 